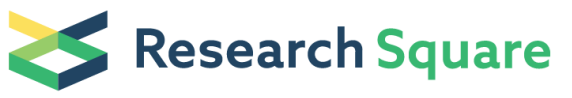

Preprints are preliminary reports that have not undergone peer review. They should not be considered conclusive, used to inform clinical practice, or referenced by the media as validated information.

\section{In silico Investigation of Saponins and Tannins as Potential Inhibitors of SARS-CoV-2 main Protease (Mpro)}

\section{Victoria Adeola Falade}

Organic Chemistry Unit, Department of Pure and Applied Chemistry, Ladoke Akintola University of Technology, Ogbomoso, Oyo State, Nigeria https://orcid.org/0000-0002-4240-1879

\section{Temitope Isaac Adelusi}

Computational Biology/Drug Discovery Laboratory, Department of Biochemistry, Ladoke Akintola University of Technology, PMB 4000, Nigeria. https://orcid.org/0000-0002-6342-8624

Ibrahim Olaide Adedotun

Biophysical and Computational Chemistry Unit, Department of Pure and Applied Chemistry, Ladoke Akintola University of Technology, Ogbomoso, Oyo State, Nigeria. https://orcid.org/0000-0002-1451-4040

\section{Misbaudeen Abdul-Hammed ( $\nabla$ mabdul-hammed@lautech.edu.ng)}

Biophysical and Computational Chemistry Unit, Department of Pure and Applied Chemistry, Ladoke Akintola University of Technology, Ogbomoso, Oyo State, Nigeria. https://orcid.org/0000-0002-5453-5858

\section{Teslim Alabi Lawal}

Biophysical and Computational Chemistry Unit, Department of Pure and Applied Chemistry, Ladoke Akintola University of Technology, Ogbomoso, Oyo State, Nigeria. https://orcid.org/0000-0001-9349-4377

\section{Saheed Alabi Agboluaje}

Department of Chemistry, Ekiti State University, Ado Ekiti, Ekiti State, Nigeria https://orcid.org/0000-00018699-8008

\section{Research Article}

Keywords: Molecular Docking, Saponins, Tannins, Pharmacokinetics, Drug-likeness, SARS-CoV-2 Mpro

Posted Date: October 28th, 2020

DOI: https://doi.org/10.21203/rs.3.rs-97021/v1

License: (1) This work is licensed under a Creative Commons Attribution 4.0 International License. Read Full License 


\section{Abstract}

It is no longer news that a novel strain of coronavirus named SARS-CoV-2 is ravaging the health sector worldwide, several attempts have been made to curtail this pandemic via repurposing of old drugs but at the present, available drugs are not adequately effective. Over the year, plant phytochemicals are increasingly becoming an alternative source of an antimicrobial agent with a novel mechanism of action and limited side effects compared to synthetic drugs. Isolated saponins and tannins were evaluated for antiviral activity against SARS-CoV-2 $\mathrm{M}^{\text {pro }}$ via Molecular Docking and it was observed that a handsome number of the phytochemicals had binding affinity much better than Remdesivir, Dexamethasone, and N3 inhibitor which were used as the standard in this study. Further Investigation of drug-likeness, ADMET profile, and bioactivity of these phytochemicals revealed that binding affinity alone is not enough in the drug discovery process and that 4 hit compounds were identified as potential inhibitors of SARS-CoV-2Mpro. This preliminary study furnishes Ellagic acid, Arjunic acid, Theasapogenol B, and Euscaphic acid as potential inhibitors of SARSCoV-2 $\mathrm{M}^{\text {pro }}$ with better pharmacokinetics and bioavailability compared to Remdesivir which is currently used compassionately.

\section{Introduction}

The outbreak of a novel strain of coronavirus has been an unprecedented challenge in the healthcare system globally. This was initially identified in a cluster of Pneumonia patients in Wuhan, Hubei province, China in December 2019 and had since spread to other continents of the world [1][2]. The causative virus was found to be closely related to a previously known Severe Acute Respiratory Syndrome Coronavirus (SARS-CoV) hence the name SARS-CoV-2 [3]. Clinical symptoms include pneumonia, cold, dry cough, sore throat, fever, shortness of breath, respiratory tract infection, headache, diarrhea, and abdominal pain [4]. Over twenty (20) million symptomatic and asymptomatic cases had been reported, with about seven hundred thousand death (https://coronavirus.jhu.edu/map.html). The infection was reported to be severe in elderly patients and more critical in individuals with underlying health conditions like diabetics, cardiovascular disease, obesity, pulmonary fibrosis, asthma, cancer, etc. [5].

As at the time of this report, no drug/vaccine has been proven to effectively cure/manage this infection. The current strategy in the management includes early diagnosis, isolation of infected individuals, maintenance of personal hygiene, physical distance, and use of personal protective equipment. Attempts have also been made to reposition/repurpose old drugs of promising antiviral potential in a bid to tackle this fast-spreading pandemic. Remdesivier, lopinavir-ritonavir, favipiravir, etc. are among the drugs used in the management of this pandemic[5]. More recently dexamethasone has been found to reduce mortality in severe cases of COVID -19[6].

increasingly becoming the alternative therapeutic and pharmacological agent of great importance in drug discovery and development. They have limited or no side effect on administration possesses a novel 
mechanism of action and great chemical diversity which enhance their therapeutic interaction with varied biological target compared to synthetic drugs.

Saponins are naturally occurring nonvolatile and surface-active glycosides of triterpenes and steroids with a wide range of pharmacological activities, including anti-inflammatory, anticancer, antiviral, antitumor, antifungal, hypoglycemic, cytotoxic activity. They are potential vaccine adjuvant due to their ability to stimulate and activate the immune system in mammals[7, 8]. The sugar side chain in saponins could be responsible for their adjuvant. Similarly, saponins have been found to possess a novel mechanism of action on the virus which involves the destruction of viral envelop, loss of binding sites, and subsequent prevention of binding of the virus to host cell[9]. They have also found application in food, confectionery, beverages, cosmetics, preparation of pharmaceutical products as well as industrial processes as surface-active and foaming agents rich source of saponins include soya beans, capsicum peppers, spinach, horse chestnut, fenugreek, ginseng, etc. $[10,11]$. The component as well as the concentration of the saponin mixture, much toxicity is observed when administered intravenously while much lower toxicity is observed when administered orally due to low absorption in the alimentary canal but it is rather hydrolyzed to sapogenins via enzymatic action[12].

Tannins on the other hands are phenolic compounds of great antioxidant potential, they are high molecular weight compounds (ranging between 500 and 3000) found in different parts of plants including leaf, stem, root, or bark [13].

This study aims at investigating the antiviral potential of selected saponins and tannins against SARS-CoV-2 Mpro through molecular docking coupled with ADMET-studied pharmacokinetic evaluation with drug likeliness at a therapeutic dose.

\section{General Experimental}

\section{Ligands preparation}

Isolated saponins include Priverogenin A, Arjunic acid, Theasapogenol B, Euscaphic Acid, Camelliagenin C, Medicagenic Acid, Protoescigenin, Arjunolic acid, Asiatic acid, Protobassic acid, Arjugenin, Polygalacic acid, Primulagenin A, Soyasapogenol B, Tomentosic acid, Presenegenin, and dexamethasone while the tannins include Punicalagin, Punicalin, Ellagic acid, Corilagin, Gallagic acid, Terflavin B. Catechin, Chebulinic acid, Hexahydroxydiphenic acid, Gallic acid, and Catechol. Standard drugs used for comparison are Remdesivir and Dexamethasone. Spartan 14 software Wave-function, was used to build the ligand molecules, after which it was minimized to obtain the most stable and lowest energy conformer, which was further optimized to obtain equilibrium geometry using the density functional theory method (DFT) at B3LYP and 6-31G* in a vacuum as the basis set.

\section{Preparation of Target Receptor}

The crystal structure of SARS-CoV-2 Mpro (PDB ID: 6lu7) was retrieved from the protein data bank (RCSB) (http://www.rcsb.org/pdb). SARS-CoV-2Mpro is the main protease of the novel strain of the 2019 
coronavirus disease. It is a protein that mediates replication and transcription of the virus, therefore the protease is often the targets of the potential inhibitor of the virus in the drug discovery and development process.

\section{Determination of (6LU7) Mpro Active Sites}

Binding pocket, ligands interactions, and all amino acid in the active site of SARS-CoV-2 Mpro were determined with Computed Atlas for Surface Topography of Proteins (CASTp) (http://sts.bioe.uic.edu/castp/index.html?2011) and Biovia Discovery Studio (2019). Obtained data were compared and validated with previously reported experimental data for SARS-CoV-2 Mpro complexed with N3 native ligand.

\section{Molecular Docking}

Water molecules, other atoms, and complexes apart from 6lu7 were removed with Biovia Discovery Studio 4.5 Client before docking. AutoDock Vina (MGL tools- 1.5.6) and Autodock Vina were used for the docking simulation, the observed grid size is 58,62 , and 40 for $x, y$, and $z$ axes, grid center is $-26.284 \times 12.603 x$ $58.960 \AA$, and $1.000 \AA$ spacing, after which docking scores and calculations were done with AutoDock Vina (MGL tools- 1.5.6), PyMOL Console Edu and Biovia Discovery studio 4.5.

\section{Assessment of ADMET and drug-like Properties}

Absorption, distribution, metabolism, and toxicity properties of the selected compounds were predicted using ADMET SAR2 web-server while drug-like features were evaluated using Molinspiration online tool (http://molinspiration.com/).

\section{Results And Discussion}

\section{Structural and Active site Analysis of COVID-19 Mpro complexed with N3 Inhibitor (PDB ID: 6LU7)}

X-ray crystallographic structure of SARS-CoV-2 Mpro (PDB ID: 6LU7) contains 306 amino acid residues complexed with an inhibitor (N3-(N-[(5-Methylisoxazol-3-YI)Carbonyl]Alanyl-L-Valyl-N 1 -((1r,2z)-4(Benzyloxy)-4-0xo-1-\{((3r)-2-Oxopyrrolidin-3-Yl]Methyl\}But-2-Enyl)-L-Leucinamide). It consists of 23\%, 31\%, $45 \%$ and $28 \%$ a-helix, $\beta$-sheets, Coil and Turns respectively. The resolution of the protease as revealed by $X-$ ray diffraction was $2.16 \AA$, crystal dimension is $a=97.93 \AA, b=79.48 \AA$ and $c=51.08 \AA$ with angles $a(900)$, $\beta$ (114.550), and $Y(900)$ respectively. R-values (free, work, and observed) are $0.235,0.202$, and 0.204 respectively while the Total Accessible Surface Area (TASA) on the protease is $14043.1(\AA)$. There are three (3) domains which are: Domain I (residues 8-110), Domain II (residues 102-184), and Domain III (residues 185-200.SARS-CoV-2 Mpro active site is located in the cleft between Domain I and II and contains a Cys-His catalytic dyad. Amino acid residue at the active site are as follows Thr24, Thr25, Thr26, His41, Met49, Tyr54, Phe140, Leu141, Asn142, Gly143, Ser144, Cys145, His163, His164, Met165, Glu166, Leu176, Pro168, His172, Asp187, Arg188, GIn189, Thr190, Ala191, and GIn192[14]. 
Recent developments in drug discovery have led to a renewed interest in the computational study which involves the use of algorithms and programs for predictions of therapeutic interventions in biological processes[15]. Molecular Docking is a structure-based drug design approach that predicts binding interactions between ligand molecules and target receptor at the binding site [16]. It is an important virtual screening tool which could screen several thousands of ligands against the target as well as identify potential inhibitors of the target receptor with speed and accuracy [17].

To investigate potential inhibitor of SARS-CoV-2 Mpro, AutoDock Vina (MGL tools- 1.5.6), PyMOL Console Edu, and Biovia Discovery studio 4.5 were used. The results obtained from the docking of selected saponins and tannins against SARS-CoV-2 Mpro were as shown in table 1 . Binding affinity is a reflection of the inhibitory activity of the plant extract against SARS-CoV-2 Mpro. It is apparent from this table that most of the selected saponins and tannins had a higher binding affinity and inhibitory activity against SARS-CoV-2 Mpro compared to Remdesivir and Dexamethasone which are standard drugs used in the management of this pandemic disease. Binding affinity (BA) for the selected saponins range between $-8.3 \mathrm{kcal} / \mathrm{mol}$ and -7.1 $\mathrm{kcal} / \mathrm{mol}$ while those of tannins range between $-9.0 \mathrm{kcal} / \mathrm{mol}$ and $-4.7 \mathrm{kcal} / \mathrm{mol}$, it can be seen that selected tannins had far greater binding affinity compared to saponins, with Punicalagin $(-9.0 \mathrm{kcal} / \mathrm{mol})$ having the outstanding inhibitory activity.

Table 1: $\quad$ Binding Affinities and inhibition constant of selected saponins and tannins 
SAPONINS

S/N Ligands

$\begin{array}{ll}\text { Binding } & \text { Inhibition Ligands } \\ \text { Affinity }(\Delta G) & \text { Constant } \\ \text { Kcal/Mol } & \end{array}$

$\left(K_{i}\right), \mu \mathrm{m}$
TANNINS
0.83
Punicalagin
$-9.0$
0.25

$-8.3$

2 Arjunic acid

$-8.1$

1.16

3 Theasapogenol

$-8.1$

1.16

B

4 Euscaphic Acid $\quad-8.0$

5 Camelliagenin C

$-7.8$

1.37

6 Medicagenic Acid

7 Protoescigenin $\quad-7.8$

8 Arjunolic acid

$-7.7$

1.93

1.93

$-7.8$

$-7.8$

1.93

2.28

$-7.7$

2.28

2.28

$-7.7$ acid

11 Dexamethasone

12 Arjugenin

$-7.6$

$-7.6$ acid

$-7.7$

2.28

2.70

2.70

2.70

14 Primulagenin A

$-7.6$

$-7.6$

2.70

16

6 Soyasapogenol B

17 Tomentosic acid

18 Presenegenin

$-7.1$

6.28

19 N3Inhibitor

$-5.6$
Punicalin

$-8.6$

0.50

Ellagic acid

$-8.4$

0.70

Corilagin

$-8.2$

0.98

Gallagic acid

$-8.1$

1.16

Affinity $(\Delta G)$

cal/Mol

$-7.6 \quad 2.70$

Remdesivir

$-7.6$

2.70

3.20

3.20

20.45

Hexahydroxydiphenic $\quad-6.4$ acid

Gallic acid

$-5.5$

93.34

N3Inhibitor

$-5.6$

78.85

$-4.7$

359.95

Catechol
2.70

2.70
Inhibition

Constant

$\left(K_{i}\right), \mu m$ 


\section{Drug-likeness Analysis of the selected compounds}

Evaluation of physicochemical properties and drug-likeness of potential active compounds is an important step in drug discovery, as proposed by Lipinski, an effective oral therapeutic drug must obey the 'rule of five' with not more than one (1) violation, this is because an orally bioavailable drug must possess molecular weight $(\mathrm{MW}) \leq 500 \mathrm{Da}$, hydrogen bond donor $(\mathrm{HBDs}) \leq 5$, hydrogen bond acceptor (HBAs) $\leq 10$ and logP (octanol-water partition coefficient) $\leq 5[18]$. These descriptors of oral bioavailability are important as they predict the permeability and absorption of such drug across a biological membrane such as an epithelium cell, partition coefficient value (LogP) is especially important in predicting intestinal absorption of such a drug[19]. Considering the first ten (10) of the tannins and saponins (Table 1) in order of binding affinity, efficacy, and safety profile using the Molinspiration online (http://www.molinspiration.com/) and ADMET SAR-2 web-server[20], Ellagic acid, Arjunic Acid, Theasapogenol B, and Euscaphic Acid were selected as hit compounds for further analysis and are coded $\mathrm{C} 1, \mathrm{C} 2, \mathrm{C} 3$, and $\mathrm{C} 4$ respectively. Although Punicalagin, Punicalin, and Priverogenin A had better inhibitory activity and binding affinity than ellagic acid, they were shunned based on toxicity and the possibility of poor absorption and permeability across a biological membrane.

Drug-likeness of the selected hits were evaluated with Molinspiration online (http://www.molinspiration.com/) as shown in Table 2, it is apparent from the table that none of the selected hits had more than one violation of the 'rule of five' which is an indication of good oral bioavailability and permeability. It is also interesting to note that the selected hit had better drug-like properties compared to Remdesivir (http://www.molinspiration.com/).

Table 2: $\quad$ Drug-Likeness of Selected Hit Compounds

\begin{tabular}{lllllll} 
Compounds & $\begin{array}{l}\text { Heavy } \\
\text { atoms } \\
(\mathrm{HA})\end{array}$ & $\begin{array}{l}\text { Molecular } \\
\text { Weight (MW) }\end{array}$ & $\begin{array}{l}\text { RO5 } \\
\text { violations }\end{array}$ & $\begin{array}{l}\text { Hydrogen bond } \\
\text { donor (HBD) }\end{array}$ & $\begin{array}{l}\text { Hydrogen bond } \\
\text { acceptor (HBA) }\end{array}$ & $\begin{array}{l}\text { miLog } \\
\text { P }\end{array}$ \\
\hline C-1 & 22 & 302.19 & 0 & 4 & 8 & 0.94 \\
\hline C-2 & 35 & 488.71 & 0 & 4 & 5 & 4.89 \\
\hline C-3 & 35 & 490.73 & 0 & 5 & 5 & 4.10 \\
\hline C-4 & 35 & 488.71 & 0 & 4 & 5 & 4.93 \\
\hline
\end{tabular}

$C-1=$ Ellagic Acid, $C-2=$ Arjunic Acid, C-3= Theasapogenol B, C-4= Euscaphic Acid

\section{ADMET properties of the selected hit}

Absorption, Distribution, Metabolism, Excretion, and Toxicity (ADMET) profile of a molecule is an important assay in the early stage of drug discovery. ADMET data enhance the selection and identification of 
molecules with optimum safety profile at a therapeutic dose along the discovery process rather than at the final stage, as this help in avoiding waste of time and precious resource on drug molecules that may eventually be discarded[21]. ADMET profile of selected saponins and tannins as computed by ADMET SAR-2 web-server [20] were as shown in Table 3, as part of the drug ADMET profile, a drug molecule should have good human intestinal absorption (HIA), solubility ( $\log S$ ) range between -1 and -5 , should be a non-inhibitor of cytochrome P450 enzyme, and should be non-Ames toxic. Others include non-carcinogenicity, noninhibition of hERG, and no or low level of toxicity [21]. All the selected hit, C1, C2, C3, and C4 are well absorbed in the human intestine, only Theasapogenol B (C3) was found to cross the blood-brain barrier, although an oral drug does not necessarily need to cross the blood-brain barrier, only central nervous system target drug need to[22]. It was also found from the prediction that all the four (4) selected hit compounds were non-inhibitor of the microsomal enzyme (cytochrome P450), which is an indication of good metabolism of the drug in the hepatocytes [23]. The potential of a drug molecule to cause mutation in DNA is revealed by Ames toxicity value and could be a major reason for excluding a drug molecule along the discovery process [24], and non-carcinogenic. Similarly, the hits compound possesses type III acute oral toxicity values (slightly toxic) which could easily be converted to type IV (nontoxic) during hit-lead optimization. The human ether-a-go-go related gene (hERG) potassium ion channel plays important role in cardiac repolarization, blockage of which may be caused by inherited mutation or some drug molecules, leading to long QT syndrome and an eventual death[25]. Interestingly all the hit compounds are not blockers of the hERG potassium channel.

Table 3: $\quad$ ADMET Prediction of Selected Compounds 


\begin{tabular}{lllll}
$\begin{array}{l}\text { Absorption\& } \\
\text { Distribution }\end{array}$ & C-1 & C-2 & C-3 & C-4 \\
\hline BBB (+/-) & 0.6372 & 0.3145 & 0.8187 & 0.5278 \\
& $($ BBB-) & $(B B B-)$ & $(B B B+)$ & $(B B B-)$ \\
\hline HIA+ & $98.15 \%$ & $96.43 \%$ & $97.21 \%$ & $97.46 \%$ \\
\hline $\begin{array}{l}\text { Aqueous } \\
\text { Solubility(LogS) }\end{array}$ & -3.144 & -4.446 & -3.753 & -4.129 \\
\hline
\end{tabular}

\section{Metabolism}

\begin{tabular}{|c|c|c|c|c|}
\hline CYP450 2C19 & 0.8017 & 0.8826 & 0.8633 & 0.8799 \\
\hline Inhibitor & Non-Inhibitor & Non-Inhibitor & Non-Inhibitor & Non-Inhibitor \\
\hline CYP450 & 0.5914 & 0.8863 & 0.8936 & 0.7582 \\
\hline Inhibitor & Non-Inhibitor & Non-Inhibitor & Non-Inhibitor & Non-Inhibitor \\
\hline CYP450 3A4 & 0.9078 & 0.8734 & 0.8723 & 0.7415 \\
\hline Inhibitor & Non-Inhibitor & Non-Inhibitor & Non-Inhibitor & Non-Inhibitor \\
\hline CYP450 2C9 & 0.5591 & 0.8938 & 0.8595 & 0.8493 \\
\hline Inhibitor & Non-Inhibitor & Non-Inhibitor & Non-Inhibitor & Non-Inhibitor \\
\hline CYP450 2D6 & 0.9575 & 0.9476 & 0.9368 & 0.9607 \\
\hline Inhibitor & Non-Inhibitor & Non-Inhibitor & Non-Inhibitor & Non-Inhibitor \\
\hline \multicolumn{5}{|l|}{ Excretion } \\
\hline \multirow[t]{2}{*}{ Biodegradation } & 0.8250 & 0.8500 & 0.9250 & 0.8250 \\
\hline & $\begin{array}{l}\text { Not } \\
\text { biodegradable }\end{array}$ & $\begin{array}{l}\text { Not } \\
\text { biodegradable }\end{array}$ & $\begin{array}{l}\text { Not } \\
\text { biodegradable }\end{array}$ & $\begin{array}{l}\text { Not } \\
\text { biodegradable }\end{array}$ \\
\hline
\end{tabular}

\section{Toxicity}

\begin{tabular}{|c|c|c|c|c|}
\hline \multirow[t]{2}{*}{ AMES Mutagenesis } & 0.8200 & 0.9000 & 0.8600 & 0.8600 \\
\hline & Non-Ames Toxic & Non-Ames Toxic & Non-Ames Toxic & Non-Ames Toxic \\
\hline \multirow[t]{2}{*}{ Acute Oral Toxicity } & 0.6020 & 0.6470 & 0.7710 & 0.7326 \\
\hline & III & III & III & III \\
\hline Eye Irritation (YES/NO) & YES & NO & NO & NO \\
\hline $\begin{array}{l}\text { Eye Corrosion } \\
\text { (YES/NO) }\end{array}$ & NO & NO & NO & NO \\
\hline hERG Inhibition & 0.8048 & 0.5631 & 0.4360 & 0.5439 \\
\hline
\end{tabular}




\begin{tabular}{lllll} 
& NO & NO & NO & NO \\
\hline Carcinogenicity & 1.0000 & 1.0000 & 0.9857 & 0.9286 \\
& $\begin{array}{l}\text { Non- } \\
\text { Carcinogenic }\end{array}$ & $\begin{array}{l}\text { Non- } \\
\text { Carcinogenic }\end{array}$ & $\begin{array}{l}\text { Non- } \\
\text { Carcinogenic }\end{array}$ & $\begin{array}{l}\text { Non- } \\
\text { Carcinogenic }\end{array}$
\end{tabular}

$C-1=$ Ellagic Acid; $C-2=$ Arjunic Acid; $C-3=$ Theasapogenol B; $C-4=$ Euscaphic Acid

\section{Bioactivity of the selected compounds}

Shown in Table 4 are the bioactivity properties of the four (4) selected hit. The inverse relationship existing between binding Energy and inhibition constant is as shown in equation 1, indicating that the higher the binding energy the lower the inhibition constant. A potential hit compound is expected to have inhibition constant values ranging between $0.1-1.0 \mu \mathrm{M}$ and not more than $10 \mathrm{nM}$ for a drug[23]. Inhibition constant values of the hit compounds range from 0.70 to $1.37 \mu \mathrm{M}$. This observation revealed that all the four (4) selected compounds are qualified as hit with Ellagic acid $(0.70 \mu \mathrm{M})$ being the most potent of all. Ligand Efficiency (LE), Fit Quality (FQ), and Ligand-efficiency-dependent lipophilicity (LELP) were also calculated according to equation $2-5$, interestingly all the hit compounds had values within the recommend fit quality $(\geq 0.8)[26]$.

$$
\begin{aligned}
& K i=e^{\left[\frac{-\Delta G}{R T}\right]}-(\text { Equation } 1) \\
& \text { Where } R=\text { Gas constant }(1.987 \times 10-3 \mathrm{kcal} / \mathrm{K}-\mathrm{mol}) ; T=298.15 \text { (Absolute Temperature); } k \text { i = Inhibition constant } \\
& \text { LigandEfficiency }(L E)=-B . E \div \text { Heavyatoms }(H . A)-----(\text { Equation } 2) \\
& L E_{\text {scale }}=0.873 e^{-0.026 \times H . A}-0.064--------------(\text { Equation } 3) \\
& F Q=L E \div L E_{\text {scale }}----------------------(\text { Eqaution } 4) \\
& L E L P=L O g P \div L E---------------------(\text { Equation } 5)
\end{aligned}
$$

Table 4: $\quad$ Bioactivity analysis of the selected compounds 


\begin{tabular}{lcccc} 
BIOACTIVITY & C-1 & C- 2 & C-3 & C- 4 \\
\hline AutoDock Vina docking score $(\mathrm{kcal} / \mathrm{mol})$ & -8.40 & -8.10 & -8.10 & -8.00 \\
\hline $\mathrm{Ki}(\mu \mathrm{M})$ & 0.70 & 1.16 & 1.16 & 1.37 \\
\hline miLog P & 0.94 & 4.89 & 4.10 & 4.80 \\
\hline Ligand Efficiency $(\mathrm{LE}) / \mathrm{kcal} / \mathrm{mol} /$ heavy atom) & 0.38 & 0.23 & 0.23 & 0.23 \\
& & & & \\
\hline LE- Scale & 0.43 & 0.29 & 0.29 & 0.29 \\
& & & & \\
\hline Fit Quality (FQ) & 0.89 & 0.81 & 0.81 & 0.80 \\
& & & & \\
\hline Ligand-efficiency-dependent lipophilicity (LELP) & 2.47 & 21.13 & 17.72 & 21.00
\end{tabular}

\section{Amino acid interaction of selected compounds}

Shown in Table 5 and Figure 1 are the docking scores including binding affinity, inhibition constant, and amino acid interaction of the selected hit compared with standard drugs, it is obvious from the table that all the selected hit compounds had a higher binding affinity to the SARS-CoV-2 Mpro and a much better inhibition constant, showing that they could be a better alternative to remdesivir and dexamethasone even with their drug-likeness and ADMET profile. It is also observed that Ellagic acid (Figure 2) was involved in hydrogen bond interaction with the SARS-CoV-2 Mpro in the same binding pocket as the native ligand N3 inhibitor with Thr190, Gln189, Glu166, Phe140, Asn142, Cys145, Gly143, and Ser144 as amino acid residue. Amino acid involved in electrostatic/hydrophobic interaction includes Glu166, Met165, Cys145, His163, Leu141, and His172. It is important to note that the Cys-His catalytic dyad interaction was also present as was in the native ligand interaction with the target receptor.

Table 5: $\quad$ Docking Score of Selected Hits 


\begin{tabular}{|c|c|c|c|c|}
\hline Ligands & $\begin{array}{l}\text { Binding } \\
\text { Affinity } \\
(\Delta G), \\
\text { kcal/mol }\end{array}$ & $\begin{array}{l}\text { COX-2 Receptor } \\
\text { amino acids forming H-bond with ligands } \\
\text { (H-Bond Distance, } A)\end{array}$ & $\begin{array}{l}\text { Electrostatic/ } \\
\text { Hydrophobic } \\
\text { Interactions } \\
\text { involved }\end{array}$ & $\begin{array}{l}\text { Inhibition } \\
\text { Constant } \\
\left(\mathrm{K}_{\mathrm{i}}\right), \mu \mathrm{M}\end{array}$ \\
\hline Remdesivir & -7.6 & 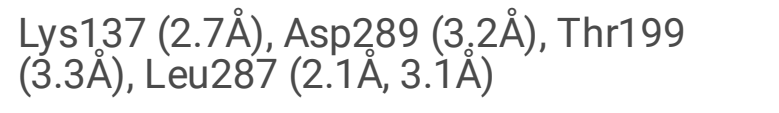 & $\begin{array}{l}\text { Tyr237, } \\
\text { Asn238 }\end{array}$ & 2.28 \\
\hline \multirow[t]{2}{*}{ Dexamethasone } & -7.7 & 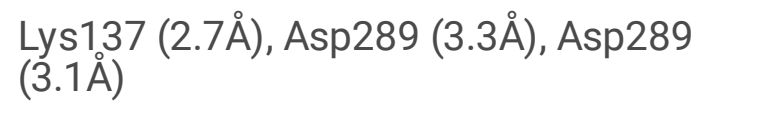 & Leu286 & 2.70 \\
\hline & & $\begin{array}{l}\text { Thr199 (3.3Å), Leu287 (2.7Å), Leu271 } \\
(3.5)\end{array}$ & & \\
\hline Ellagic acid & -8.4 & 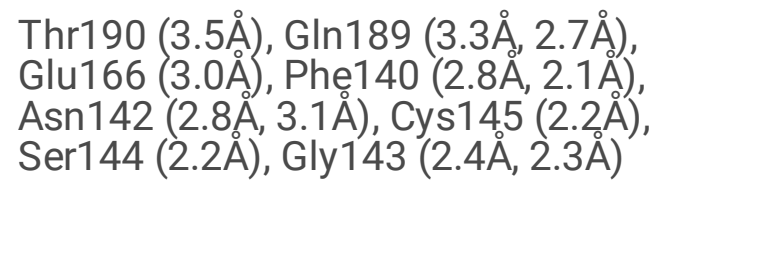 & $\begin{array}{l}\text { Glu166, } \\
\text { Met165, } \\
\text { Cys145, } \\
\text { His163, } \\
\text { Leu141, } \\
\text { His172 }\end{array}$ & 0.25 \\
\hline Arjunic acid & -8.1 & $\begin{array}{l}\text { Asp289 (3.2Å), } \\
\text { Leu287 (3.2Å) }\end{array}$ & $\begin{array}{l}\text { Leu272, } \\
\text { Leu286 }\end{array}$ & 1.16 \\
\hline $\begin{array}{l}\text { Theasapogenol } \\
\text { B }\end{array}$ & -8.1 & 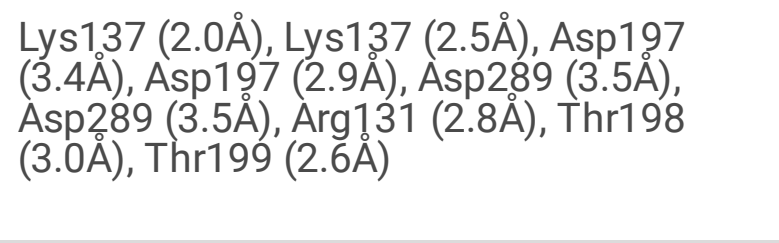 & $\begin{array}{l}\text { Tyr239, } \\
\text { Leu272, } \\
\text { Met276, } \\
\text { Leu286, } \\
\text { Leu287 }\end{array}$ & 1.16 \\
\hline Euscaphic Acid & -8.0 & 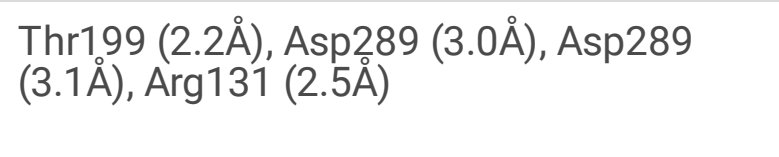 & $\begin{array}{l}\text { Leu272, } \\
\text { Leu286, } \\
\text { Leu287 }\end{array}$ & 1.37 \\
\hline
\end{tabular}

Figure 1: The bar chart showing the binding energies and inhibition constants of selected hits as significant potential inhibitor of SARS-CoV-2 main protease

Figure 2: $\quad$ Amino acid interactions of Ellagic acid with the active site (binding pocket) of SARS-CoV-2 main protease

\section{Conclusion}

This study evaluates saponins and tannins against SARS-CoV-2 Mpro via in silico studies. The results obtained flourishes Ellagic acid, Arjunic acid, Theasapogenol B, and Euscaphic Acid as probable inhibitors of SARS-CoV-2 Mpro. Therefore, functional foods/nutraceuticals blessed with these compounds could be used in the development of a new therapeutic drug/vaccine towards managing/treating COVID-19 disease. 


\section{Declarations}

\section{Acknowledgments}

The authors wish to acknowledge members of the Computational and Biophysical Chemistry group in the Department of Pure and Applied Chemistry, Ladoke Akintola University of Technology, LAUTECH, Ogbomoso, Nigeria.

\section{Funding}

The author(s) received no financial aid or support in any form for this research work.

\section{Conflicts of Interest}

The authors declare that there is no conflict of interest in this manuscript.

\section{Authors' contributions}

1. A. Falade and I. O. Adedotun: Conceptualization, Writing - Original Draft, Writing-Review \& Editing, Methodology, Investigation, Data curation, Visualization

2. Abdul-Hammed and A. T. Isaac: Conceptualization, Methodology, Validation, Supervision, Writing-Review \& Editing, Visualization, Data curation, Resources

3. A. Lawal and S. A. Agboluaje: Conceptualization, Methodology, Data curation, Investigation, Visualization

\section{References}

1. Zhou P, Yang X, Wang X, et al (2020) A pneumonia outbreak associated with a new coronavirus of probable bat origin. Nature 579: 270-273. https://doi.org/10.1038/s41586-020-2012-7

2. Chang L, Yan Y, Wang L (2020) Coronavirus Disease 2019: Coronaviruses and Blood Safety. Transfus. Med. Rev.34(2): 75-80. https://doi.org/10.1016/j.tmrv.2020.02.003

3. Wang M, Cao R, Zhang L, et al (2020) Remdesivir and chloroquine effectively inhibit the recently emerged novel coronavirus (2019-nCoV) in vitro. Cell Res. 30:269-271. https://doi.org/10.1038/s41422020-0282-0

4. Chen N, Zhou M, Dong X, et al (2020) Epidemiological and clinical characteristics of 99 cases of 2019 novel coronavirus pneumonia in Wuhan, China: a descriptive study. Lancet 395:507-513. https://doi.org/10.1016/S0140-6736(20)30211-7

5. Wu R, Wang L, Kuo HCD, et al (2020) An Update on Current Therapeutic Drugs Treating COVID-19. Curr Pharmacol Reports. 1-15. https://doi.org/10.1007/s40495-020-00216-7 
6. Johnson RM, Vinetz JM (2020) Dexamethasone in the management of covid -19. BMJ 370:1-2 doi: https://doi.org/10.1136/bmj.m264

7. Sun H, Xie Y, Ye Y (2009) Advances in saponin-based adjuvants. Vaccine. 27(12):1787-1796. https://doi.org/10.1016/j.vaccine.2009.01.091

8. Skene CD, Sutton P (2006) Saponin-adjuvanted particulate vaccines for clinical use. Methods. 40(1):5359. https://doi.org/10.1016/j.ymeth.2006.05.019

9. Roner MR, Sprayberry J, Spinks M, Dhanji S (2007) Antiviral activity obtained from aqueous extracts of the Chilean soapbark tree ( Quillaja saponaria Molina ). J Gen Virol. 88(1): 275-285. https://doi.org/10.1099/vir.0.82321-0

10. Francis G, Kerem Z, Makkar HPS, Becker K (2002) The biological action of saponins in animal systems: a review. 88(6): 587-605. https://doi.org/10.1079/BJN2002725

11. Vincken J, Heng L, Groot A De, Gruppen H (2007) Saponins, classification and occurrence in the plant kingdom. 68(3): 275-297. https://doi.org/10.1016/j.phytochem.2006.10.008

12. Guclu-Ustundag Ö, Mazza G (2007) Saponins: Properties, applications and processing. Crit Rev Food Sci Nutr 47(3): 231-258. https://doi.org/10.1080/10408390600698197

13. Serrano J, Puupponen-pimiä R, Dauer A, Aura A (2009) Review Tannins: Current knowledge of food sources, intake, bioavailability and biological effects. 310-329.

https://doi.org/10.1002/mnfr.200900039

14. Jin Z, Du X, Xu Y, et al (2020) Structure of Mpro from COVID-19 virus and discovery of its inhibitors. Nature 582: 289-293. https://doi.org/10.1038/s41586-020-2223-y

15. Shoichet BK, McGovern SL, Wei B, Irwin JJ (2002) Lead discovery using molecular docking. Curr. Opin. Chem. Biol. 6: 439-446. https://doi.org/10.1016/s1367-5931(02)00339-3

16. Ferreira LG, Santos RN, Oliva G, Andricopulo AD (2015) Molecular Docking and Structure-Based Drug Design Strategies. Molecules 20: 13384-13421. https://doi.org/10.3390/molecules200713384

17. Dias R, Filgueira W, Jr DA (2008) Molecular Docking Algorithms. 9(12): 1040-1047. https:/doi.org/10.2174/138945008786949432

18. Lipinski CA (2004) Lead profiling Lead- and drug-like compounds: the rule-of-five revolution. Drug Discov Today 1(4): 337-341. https://doi.org/10.1016/j.ddtec.2004.11.007

19. Aucamp M, Odendaal R, Liebenberg W, Hamman J (2015) Amorphous azithromycin with improved aqueous solubility and intestinal membrane permeability. Drug Dev Ind Pharm 41(7): 1100-1108. https://doi.org/10.3109/03639045.2014.931967

20. Cheng F, Li W, Zhou Y, et al (2012) admetSAR: A Comprehensive Source and Free Tool for Assessment of Chemical ADMET Properties. J Chem Inf Model 52(11): 3099-3105. https://doi.org/10.1021/ci300367a

21. Tsaioun K, Kates SA (2010) ADMET for Medicinal Chemists: A Practical Guide. John Wiley and Sons, Singapore 145-200. https://doi.org/ 10.1002/9780470915110

22. Hughes JP, Rees S, Kalindjian SB, Philpott KL (2011) Principles of early drug. Br J Pharmacol 162: 12391249. https://doi.org/10.1111/j.1476-5381.2010.01127.x 
23. Stevens E (2014) Lead Discovery. In: Jaworski A (ed) Medicinal Chemistry: Modern Drug Discovery Process. Pearson, pp 247-272

24. Mccarren P, Springer C, Whitehead L (2011) An investigation into pharmaceutically relevant mutagenicity data and the influence on Ames predictive potential. J Cheminform 3(51): 1-20. https://doi.org/10.1186/1758-2946-3-51

25. Sanguinetti MC, Tristani-firouzi M (2006) hERG potassium channels and cardiac arrhythmia. Nature 440:463-469. https://doi.org/10.1038/nature04710

26. Hopkins AL, Keserü GM, Leeson PD, et al (2014) The role of ligand efficiency metrics in drug discovery. Nat Rev Drug Discov 13(2): 105-121. https://doi.org/10.1038/nrd4163

\section{Figures}

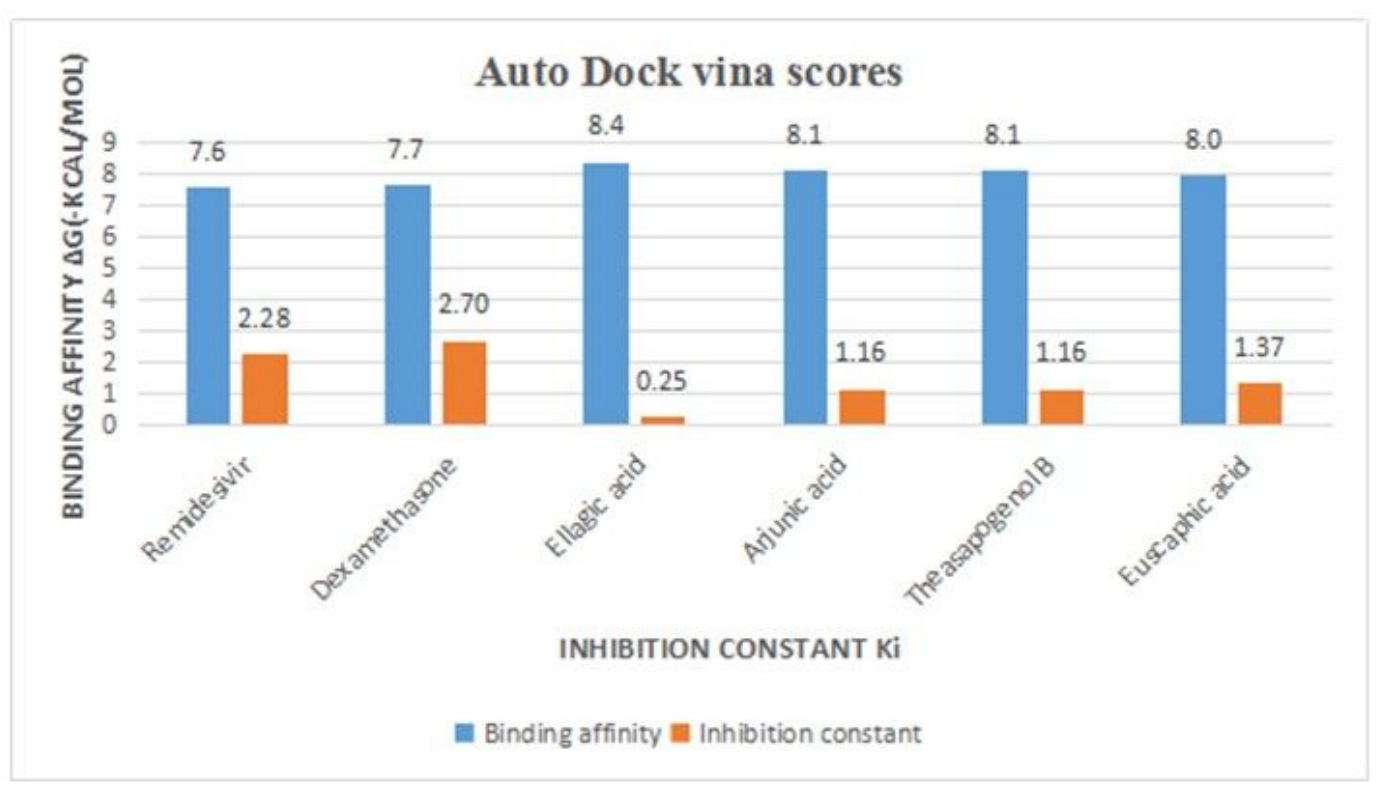

Figure 1 
The bar chart showing the binding energies and inhibition constants of selected hits as significant potential inhibitor of SARS-CoV-2 main protease

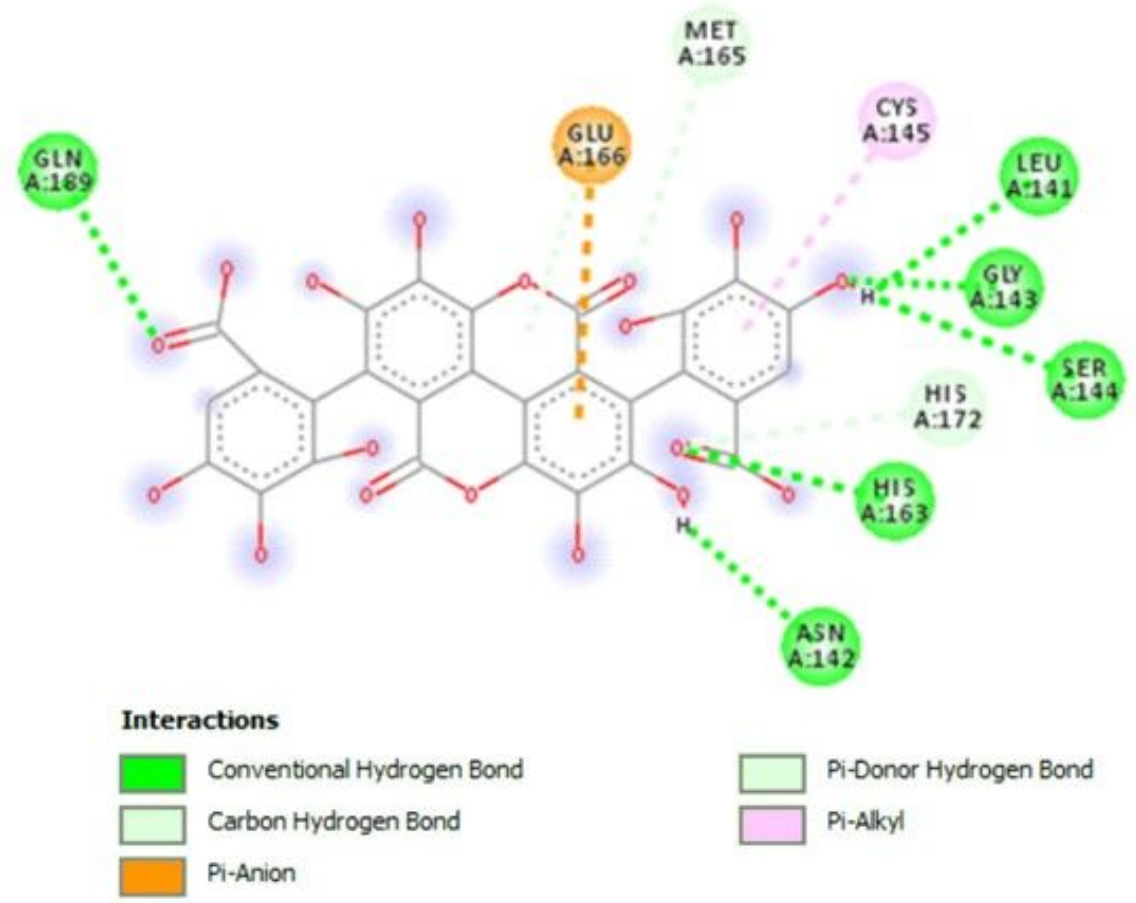

\section{Figure 2}

Amino acid interactions of Ellagic acid with the active site (binding pocket) of SARS-CoV-2 main protease 